\title{
Helping patients make better decisions: how to apply behavioral economics in clinical practice
}

\author{
Maureen Reni Courtney' \\ Christy Spivey ${ }^{2}$ \\ Kathy M Daniel' \\ 'College of Nursing, ${ }^{2}$ College \\ of Business, University of Texas \\ at Arlington, Arlington, TX, USA
}

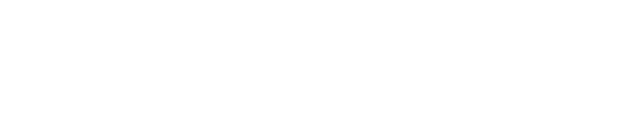

\begin{abstract}
Clinicians are committed to effectively educating patients and helping them to make sound decisions concerning their own health care. However, how do clinicians determine what is effective education? How do they present information clearly and in a manner that patients understand and can use to make informed decisions? Behavioral economics (BE) is a subfield of economics that can assist clinicians to better understand how individuals actually make decisions. BE research can help guide interactions with patients so that information is presented and discussed in a more deliberate and impactful way. We can be more effective providers of care when we understand the factors that influence how our patients make decisions, factors of which we may have been largely unaware. BE research that focuses on health care and medical decision making is becoming more widely known, and what has been reported suggests that $\mathrm{BE}$ interventions can be effective in the medical realm. The purpose of this article is to provide clinicians with an overview of BE decision science and derived practice strategies to promote more effective behavior change in patients.
\end{abstract}

Keywords: nursing, message framing, defaults, incentives, social norms, commitment devices, health care

\section{Introduction}

Clinicians are committed to effectively educating patients and helping them to make sound decisions concerning their own health care. However, how do clinicians determine what is effective education? How do they present information clearly and in a manner that patients understand and can use to make informed decisions? Patients make decisions daily, such as choosing a treatment, agreeing to surgery, and managing their disease. Clinicians believe their responsibility is to provide accurate and understandable information to patients so they can make the best personal decisions. After all, patients are rational beings and, given the facts, will make good decisions that will help them to achieve health goals. One would like to think this is the way patients make decisions, but we know from experience that is often not the case.

Behavioral economics (BE) is a subfield of economics that can assist clinicians to better understand how individuals actually make decisions. BE research can help guide interactions with patients so that information is presented and discussed in a more deliberate and impactful way. We can be more effective providers of care when we understand the factors examined in research that influence how our patients make decisions, factors of which we may have been largely unaware. The purpose of this article is to provide clinicians with an overview of BE decision science and derived practice strategies to promote more effective behavior change in patients.

The first applications of BE to health centered around understanding addictive behaviors such as smoking. More recently, researchers have begun to explore the potential of BE to increase patient welfare, improve quality of care, and decrease costs
Correspondence: Maureen Reni Courtney College of Nursing, University of Texas at Arlington, 4II S. Nedderman St, Arlington, TX 76016, USA

Tel +I 8172722776

Email maureen@uta.edu 
through its application to medical decision making. ${ }^{1}$ What has been reported thus far suggests that selected BE interventions can be effective in the medical realm. ${ }^{1}$ For example, a substantial thread of literature consistently finds that how information regarding the benefits and risks of a medical procedure is presented to a patient (a BE technique called framing) will impact their decision about whether to undergo a procedure. ${ }^{2-7}$ This evidence will be discussed in greater detail later in the manuscript. A recent study even finds that how information about the costs and quality of health care providers and hospitals is presented to patients impacts the likelihood that they choose high-value (high quality and low cost) care. ${ }^{8}$ Several BE techniques have shown to be effective at reducing costs by influencing behavior surrounding prescription medications. ${ }^{9}$

Of late, there is an increase in research that tests new ways of applying BE to health and health care, a promising development given that the untapped potential seems vast. These include using BE to discourage the demand for low-value or unnecessary health services, to encourage practitioners to follow best practice recommendations and guidelines, and to empower patients through a combination of knowledge and skills to engage in shared decision making with their health care providers. ${ }^{9,10}$

Though forthcoming research will undoubtedly enhance our knowledge of how best to use certain BE techniques, the existing research findings about human behavior are compelling and provide opportunity for application in clinical practice. Nevertheless, very few studies were found in the nursing literature that have used BE concepts as a framework to develop interventions. ${ }^{7}$ It is our hope that this article may motivate nursing clinicians and researchers to consider the use of BE in their practice. If used successfully on a wide scale, BE techniques could have an impact on both the cost and quality of health care and desired patient outcomes.

\section{BE: the basics}

$\mathrm{BE}$, a relatively new and growing field of economics, focuses on understanding human behavior and decision making. It is heavily informed by psychology and emphasizes that the context in which a decision is made is important. BE aids in explaining human behavior that cannot be explained by neoclassical (traditional) economic theory, which posits that humans make rational choices that maximize their utility (satisfaction) subject to constraints (such as monetary or time constraints). The rationality assumption in traditional economic theory may not be appropriate for understanding many of the decisions made by individuals, and therefore can provide a limited approach to prediction. In contrast, $\mathrm{BE}$ as a field can be thought of as 1) a collection of insights and research findings that have been developed about human behavior that would not be considered rational by traditional economic theory, and 2) a collection of techniques that harness these insights to influence behavior to achieve an outcome that is believed beneficial to an individual. ${ }^{1}$

BE recognizes, based on research findings, that people's decisions are influenced by many factors. In fact, people:

- are not always rational and do not always act in their own best interest or make decisions based on emotion or affect, and thus are more receptive to anecdotes and stories than to statistics; ${ }^{11}$

- adopt rules of thumb to deal with limited informationprocessing capacity;

- are overly confident and optimistic in certain situations;

- pay more attention to information that seems relevant (salient) to them;

- tend to follow through with promises that are made publicly;

- tend toward inertia of actions, willingly accepting preset options (defaults);

- are loss-averse, such that losing something causes more mental anguish than gaining something of the same value;

- are strongly influenced by the manner in which information is presented to them and who communicates the information (framing);

- respond to incentives;

- have present-biased preferences, which means that present benefits and costs are valued more than future benefits and costs. Thus, an immediate reward of $\$ 10$ is valued more than a future reward of the same amount, and an immediate cost of $\$ 10$ feels larger than a future cost of $\$ 10$;

- respond to social pressure and are heavily influenced by the (perceived) actions of those around them. ${ }^{12}$

To expand on that information, decisions are not always or even often based on a careful, logical examination of a situation and are far more intuitive than is appreciated. In fact, Kahneman ${ }^{13}$ claims that these intuitive decisions far outnumber instances of more deliberative decision making. Humans are proposed to make decisions in one of two states: system 1 (fast) or system 2 (slow). System 1 thinking and decision making is fast, intuitive, and often influenced strongly by emotions. It uses quick perceptions and memory and may be quite uncritical of new information. In contrast, system 2 thinking is slower, more deliberative, and typically logical. ${ }^{13}$ The major point is that most people believe they function 
most often using system 2 deliberate, logical thinking, when research shows, in fact, they do not. Understanding the type of thinking style a person is using at a given point is important. For example, patients often make decisions based on emotion or affect (system 1), and thus may be more receptive to learning by anecdotes and stories than by statistics. ${ }^{11}$

Clinicians may mistakenly assume their patients are using system 2 thinking to examine and understand the logic of their disease and their required self-management. To encourage increased use of system 2 thinking involves asking people to make comparisons or creating doubt about what they know or understand. ${ }^{13}$ Therefore, asking a patient to compare his or her understanding of two treatment options might foster a shift from quick system 1 thinking to deliberate system 2 thinking and result in a more carefully considered choice. Ongoing research can assist clinicians to better consider these different thinking styles.

Researchers and practitioners can use this knowledge about human behavior to encourage an individual to make a choice that is in his or her best interest that he or she otherwise might not make. BE techniques or tools such as monetary incentives, commitment devices, framing of information, defaults, and social norms are powerful strategies and are discussed in this review.

\section{Monetary and other incentives}

A number of corporations have offered employees monetary incentives to lose weight or stop smoking. Evidence on the effectiveness of monetary incentives is somewhat mixed, but it is clear they can have at least a modest impact. ${ }^{14,15}$ Employees may be offered a small monetary reward for each percentage of body weight lost until a goal is reached, and they may even be offered maintenance incentives. For example, each month, employees who maintain their goal weight may be entered into a drawing to receive a prize.

One obvious drawback is the cost. It can take monetary incentives over a long period of time to have the desired impact. In the case of smoking cessation, larger incentives may be offered at first, to help individuals make it through the initial withdrawal, with smaller incentives offered later when the value of quitting smoking becomes more salient and is not overshadowed by the withdrawal phase.

Another example of a monetary incentive to curb smoking is charging a higher health insurance premium to smokers, an increasingly common practice. The Affordable Care Act allows employers to use up to $30 \%$ of the cost of employee premiums for health-related incentives and up to $50 \%$ if the employer includes a nonsmoking incentive. ${ }^{16}$
Research suggests that context matters when it comes to monetary incentives. They can backfire in certain situations, such as if a high-value monetary incentive induces pressure, stress, or nervousness so that performance actually degrades, or if a temporary monetary incentive is offered for a task like completing puzzles that is considered interesting or enjoyable. ${ }^{17}$ Thus, while incentives can, in some situations, encourage positive behaviors, in other circumstances, providing incentives can be counterproductive.

Incentives other than monetary may be considered in clinical practice. Creative ideas can include such things as patient-identified rewards for reaching a goal (eg, buying a new outfit, attending a spa, getting a massage). The practice could bring in a nail therapist to schedule free manicures for an afternoon for those patients who have achieved a goal. Or the practice could request a testimonial from a patient to feature on the website in recognition of a behavior achieved, which could be a strong incentive to that patient and to others.

$\mathrm{BE}$ research teaches us that incentives that are meaningful can be a valuable tool to assist patients to achieve outcomes, yet these are not often used in clinical practice. Talk to your patients to see what they identify as rewards worth pursuing.

\section{Commitment devices}

Because of present-biased preferences, individuals are more willing to commit to a future action than they are to a present action. This explains the familiar scenario of delaying a diet commitment until next week. Researchers and practitioners can take advantage of this well-documented behavioral quirk by offering patients choices about future behavior, before the time that they have to take an action. Loewenstein et $\mathrm{al}^{18}$ suggest two examples. Patients can be contacted to schedule regular exams or labs well ahead of time and accept a financial penalty for canceling within a certain amount of time. Or, for those trying to lose weight, vending machines in the workplace could be programmed with a personal code, such that individuals cannot access the machine the next day or for a specified time in the future.

Another example of a commitment device for losing weight is to have individuals deposit a lump sum amount in an account not in their control before undertaking a weight loss program. If the individual does not meet their intermediate goal at a specific point in time, then a preset amount is deducted from the account. The individual will not receive this money, and it could even be donated to a charity that the individual would not typically support. ${ }^{19}$ Such a device appeals to the fact that people are loss-averse; they do not 
want to lose money or something they already own. The UK's Behavioural Insights Team has partnered with the drugstore chain Boots to implement a similar program to encourage smoking cessation. ${ }^{20}$

Commitments do not have to involve depositing money ahead of time, and, in fact, rewards or penalties are not necessarily needed to achieve behavior change. ${ }^{21}$ Commitments can be as simple as asking for a signed pledge or a verbal commitment, preferably in the presence of someone the signee respects. ${ }^{22}$ Williams et $\mathrm{al}^{22}$ found that a signed commitment to an exercise goal yielded success over 6 weeks more often than in a control group that was given a walking program but did not enter into an agreement.

Ask your patients to make a commitment regarding a new therapy, a new exercise program, or a new behavior such as reading food labels. Ask them to sign a pledge and tell their family members what they will be doing. Explain to them that these commitments can help them to be more successful.

\section{Framing}

The way in which information is delivered matters to how individuals make choices. For example, the likelihood of an individual choosing to have a surgical procedure can be differentially impacted depending on how the potential outcome of the procedure is described. Patients who are told a procedure has a 5\% mortality rate (loss-framed) are more likely to avoid the procedure than patients who are told the procedure has a 95\% survival rate (gain-framed). The information presented is basically the same but is framed differently. McNeil et $\mathrm{al}^{23}$ suggest this difference has much to do with our aversion to potential loss.

Using either loss-framed or gain-framed messaging to aid decision making is better than providing no frame at all. In the context of encouraging employees to make decisions about their benefits, Moses ${ }^{24}$ argues that most messages to employees can and should be framed. For example, the following information is not framed: "This year we are offering a high-deductible health plan with a health savings account." Instead, he argues messages should be framed to highlight what employees might gain or lose. For example, "The highdeductible health plan provides medical coverage for your family today, plus a health savings account for tomorrow." is gain-framed. An alternative message, "Are you really going to pass up the $\$ 500$ we have in place for you when you enroll in the high-deductible health plan?" is loss-framed.

Most messages to patients regarding their health should be framed. Whether loss-framed messages or gain-framed messages will have more impact depends upon the situation. Evidence suggests that loss-framed messages work better to promote detection procedures such as mammograms or sexually transmitted disease screenings. ${ }^{2}$ Here is an example of a loss-framed message: avoiding sexually transmitted disease screening can cause you to reduce or lose your fertility due to undetected infections. We argue that loss-framed messages will also likely be more effective to discourage unnecessary exams and treatment, such as avoiding unnecessary X-rays to reduce radiation. On the other hand, gain-framed messages seem to be more effective in promoting certain prevention behaviors, ${ }^{3-5}$ such as using sunscreen, ${ }^{6}$ carrying out proper foot care with diabetes, ${ }^{7}$ and using condoms. ${ }^{2}$ Here is an example of gain-framing a prevention behavior message: sunscreen can protect your face and maintain a more youthful appearance. However, this delineation is not always clear, and the patient's own outlook may affect which type of framing works better. For example, $\operatorname{Moses}^{24}$ has found that patients who are skeptical of health claims respond more to loss-framed messages, as promises of future benefits serve only to increase doubt and skepticism. Nevertheless, we can assume that most individuals are loss-averse, indicating lossframing will be more effective, holding all else constant.

Positive (ie, gain-framed) outcomes versus negative (ie, loss-framed) outcomes messages can be developed for your patients describing expected medication side effects, disease management monitoring, and many other topics discussed daily with patients. See Table 1 for an example of a gainframed and loss-framed message to patients about getting their annual flu shot.

Using BE, clinicians can make a deliberate choice in how to frame hazard or risk information (see Table 1). This is an important area for clinical research, as framing health information is such a daily aspect of educating patients. Moreover, no individual is predictably immune to framing, regardless of age or education level, as it simply has to do with how humans process information. Making the effort to deliberately frame a message can have a measureable impact. Current national and health system efforts to develop and use patient decision aids should incorporate $\mathrm{BE}$ research on information framing into their messages. ${ }^{25}$

\section{Defaults}

Default settings matter when it comes to making choices, largely due to well-documented characteristics of human decision making such as inertia, aversion to change, or fear of making a "bad" decision. Employees are much more likely to contribute to a retirement plan when they are automatically 
Table I Examples of behavioral economics used for common clinical questions

How can I best encourage my patients to get an influenza immunization?

Framing examples:

Instead of saying "It's time to get a flu shot.", use framing:

"Set a good example for your family and get peace of mind. Get your flu shot." (gain frame) or "Your family needs you to be healthy, now and later, so get your flu shot." (loss frame). In the context of flu shots, the desire to avoid regret is a powerful motivator.

Norms example:

"Last year, over xx\% of my patients (or patients at this clinic) got a flu shot." The more similar the comparison group to the patient, the better. Note: this assumes the number is quite high. What if the numbers are not so great? Tell a story about a patient who regretted not getting the shot or one who ended up being really grateful to have had it.

Is it better to explain the risks of a treatment first and then the expected benefits or vice versa? Does the explanation sequence matter?

Default example:

If a patient has no strong preference, the order of treatment options may matter, as they may choose the first option mentioned, especially if it is perceived as a recommendation.

How can I help my patient to understand their disease risk level? Are numbers or pictures better?

Framing example: Pictures can often better convey individual risk level, as many patients can relate to these more easily than to statistics. Picture tables of risk can be found at http://www.npc.nhs.uk/therapeutics/cardio/cd_lipids/resources/pda_Lipids.pdf, ${ }^{40}$ which can be used to explain someone's personal risk of heart attack when using statins.

enrolled and have to opt out if they do not want to participate, as opposed to having to opt in if they want to participate. ${ }^{26}$

Another well-known use of default settings is promoting organ donation. Individuals are much more likely to agree to become organ donors when it is the default option and they are not required to opt in to participate. Instead, they must opt out if they do not want to become an organ donor. Such programs have been successful in several European countries, such as France and Portugal, where almost all adults are registered organ donors, compared with about $20 \%$ in the UK, where individuals have to opt in. In addition, a number of US states use prompted choice, where citizens must check a box when they apply for a driver's licence, indicating whether or not they want to be an organ donor. The UK also implemented prompted choice. ${ }^{27}$

Default settings are all around us, built into many institutions' policies. For example, employees need to opt in if they want to contribute to a health care flexible spending account. Drug prescriptions default to generic medication unless specified otherwise by the physician. The Centers for Disease Control and Prevention has recommended human immunodeficiency virus testing for all patients aged 15-65 years as part of routine care, unless they opt out. ${ }^{28}$

Default settings are more effective when individuals do not have strong preferences over a decision to be made. ${ }^{29}$ When strong preferences are absent, individuals may simply choose the first alternative presented to them, especially if it is interpreted as a recommendation. Practitioners present treatment options to patients in some order, a default ordering, so why not strategically choose the order in which options are presented, for the benefit of the patient?
Not using defaults to the benefit of patients, where appropriate, is a missed opportunity. We specify "where appropriate" because there are invariably some cases where setting a default option is not preferred; instead, we may want an active choice to be required. For example, a default drug dose in a computerized order entry system may result in more dosage errors than asking a physician or pharmacist to actively enter the specific dosage required. ${ }^{30}$

Participation in a behavior can be predictably enhanced based on the structure of choice that is offered, without restricting the options available to patients. Health care providers should examine existing defaults within their institutions to ensure they are enhancing the welfare of patients, as well as consider putting other defaults into place.

\section{Social norms}

People's actions are influenced by what they perceive others around them are doing. This is largely because the more we believe others to be taking a certain action, the more we think that action must be correct and that we can avoid making a mistake by following the same action. We know that people are more likely to gain weight when others in the same social networks are doing so. ${ }^{31}$ College students consistently overestimate how much fellow students drink. ${ }^{32}$ In 1994, the University of Arizona set out to educate its students about the real level of college student drinking through a social norm campaign using posters, flyers, and word of mouth. In the subsequent 3 years, heavy drinking significantly declined. ${ }^{33}$

In the 1990s, about 10\% of Minnesota citizens were not paying state taxes, so the state sent the delinquent taxpayers 
one of two letters. One letter described that taxes were used for public services that benefited all citizens, like education and law enforcement; the other letter used a social norm and shared that more than $90 \%$ paid all state taxes. The social norm letter was significantly more effective than the descriptive letter in getting people to submit their state tax payments on time. ${ }^{34}$

Adjusting perceptions of social norms can be a simple and effective way to change behavior. For example, Zimmerman ${ }^{35}$ suggests that practitioners can help patients with below average physical activity levels do more exercise by communicating to them average levels among the population. A practice could tell patients how many other patients have signed an exercise pledge and/or post on their website. Humans are very influenced by what others are doing, and we can use this fact to educate and assist our patients. Or simply sharing a story of similar patients (such as single moms or seniors) who have successfully increased activity levels makes such a scenario seem normative.

In fact, stories can be powerful motivators. Presentation of a jaw-dropping statistic intended to shock people into action can be quite ineffective (ie, one in eight women will get breast cancer in their lifetime), especially for those who are not quantitatively inclined. Instead, an individual's story has the power to evoke strong emotions that, for many, are much more likely to lead to action than would hearing faceless statistics. Another suggestion for practitioners is to gather patient testimonials regarding their success and post them on the practice's website or on a screen in the waiting room. See Table 1 for information on how to use social norms to encourage patients to get their flu shot.

\section{The ethics of BE}

The ethics of BE interventions may be of concern to some, such that BE might be viewed as manipulation or a return to paternalistic health care. It should be noted that $\mathrm{BE}$ is often used to encourage individuals to make evidencebased decisions that are undoubtedly in their best interest, such as participating in a weight loss program or smoking cessation. This rests on the pivotal observation that people simply do not always make such decisions for themselves. BE techniques make use of well-known foibles in human decision making to encourage individuals to make these decisions for themselves. BE techniques that promote the well-being of individuals or society as a whole, when there is no question that a specific action will do so (such as wearing seatbelts or smoking cessation), are therefore not very controversial.
In some situations, what is in the best interest of the patient or what is consistent with patient preferences may be in question. This is particularly true when it comes to using defaults in clinical decision making. In the case of defaults, not restricting the options of individuals and making sure individuals are well informed about the options, when possible, are key to their ethical acceptability. Taking that notion further, practical barriers to opting out of the default, such as paperwork, should be minimized. Otherwise, an argument can be made that the default option does restrict choice. For example, in Wisconsin, the default in $15 \%$ of nursing homes is that cardiopulmonary resuscitation (CPR) will be performed only on an opt-in basis. ${ }^{36}$ Halpern et $\mathrm{al}^{37}$ argue that unless residents are alerted to this policy upon arrival, their right to make a choice is not preserved. However, patients may not be able to make a choice for themselves in some cases, such as in the case of arriving at a hospital after a stroke.

To further examine the ethics of using defaults, a recent study found that about $23 \%$ of older adults would not want to receive the clot-busting medication tissue plasminogen activator after a stroke if they were unable to make the decision themselves after arriving at the hospital. ${ }^{38}$ The drug is not life saving but it is associated with better mental functioning and an increased likelihood of being able to live independently poststroke. The American Academy of Neurology and the American Heart Association/American Stroke Association have released statements supporting the use of the drug for stroke patients who are unable to decide, who do not have a family member present, and who do not have an advance directive (AD) in place. These statements amount to supporting administration of the drug as the default option. Yet less than $5 \%$ of stroke patients receive the medication.

The same study found that only $24 \%$ of older adults would not want a paramedic to perform CPR after a cardiac arrest. Yet CPR is a commonly accepted default when medical staff do not know the wishes of the patient.

The controversy in making administration of the drug a default arises because the drug is time sensitive and not without risks. It should only be given within a few hours of a stroke, and there is a risk of bleeding. It is likely that the risks and/or uncertainty about the timing of a stroke are the main reasons behind such a small fraction of patients receiving the medication. A doctor may not want to be responsible for a poor outcome due to bleeding. So should the decision continue to be left up to doctors, with a result that very few patients get the medicine? Or should hospitals make administration of the drug a default for eligible patients in accordance with the preferences of $77 \%$ of individuals? These questions 
highlight the tensions between the pitfalls and the benefits of using defaults in certain cases.

Thus, when potential BE policies and techniques are being considered, the following two questions should be answered: 1) is the purpose of the BE policy or technique to benefit the well-being of patients (as opposed to benefiting the institution/practitioner implementing it, such as to lower costs), and 2) does a single action (such as a treatment) benefit all patients with a particular ailment (or only a subset)? If the answer to one of the questions is "no", then the policy or technique should be carefully considered and care should be taken to preserve patient autonomy. BE policymakers as well as medical practitioners should be guided by the ultimate goal of making individuals who engage in harmful behaviors better off without harming those who do not, all while preserving individual choice.

Also, note that some BE techniques such as framing or information regarding social norms are simply ways of delivering information to individuals, just in a targeted way. This information should always be factual and never intended to mislead. For example, a clinician should never employ a social norm strategy by telling a patient that $90 \%$ of his or her patients got a flu vaccine this year if, in fact, the truth is only $45 \%$.

Using BE responsibly is not detrimental. On the contrary, do clinicians not owe patients interventions that include an understanding of science-based decision making? Continuing to provide interventions without benefit of decision-making science provided through $\mathrm{BE}$ research can be a disservice to patients. BE techniques should preserve the opportunity for the patient to make a choice, and in the end the patient must make the final decision. Ethical clinicians will use BE techniques responsibly with their patient's best interests always a priority. Unethical clinicians may distort or withhold information. However, these are not BE techniques but, rather, examples of unethical behaviors in general. Halpern ${ }^{39}$ sums it up well when he states that:

As long as the nudges are true nudges, where a decisionmaker is free to choose otherwise, then we are likely to achieve a great deal more good by helping overburdened people make decisions that are likely to be consistent with their goals. ${ }^{39}$

\section{Applying selected BE techniques to a common practice example:ADs}

To this point, the paper has examined various $\mathrm{BE}$ techniques with application to a variety of clinical situations. In contrast, the discussion to follow provides examples of several $\mathrm{BE}$ techniques applied to one practice example that many clinicians, patients, and families face: ADs. Understanding the range of $\mathrm{BE}$ options that can be used in a specific practice situation can enrich one's facility using BE and provides a useful review of major techniques.

Making choices about advanced care planning has been encouraged for many years since the Patient Self Determination Act of 1990. Despite all the campaigns and publicity around this issue, less than $40 \%$ of patients have an advanced care plan at the time of hospital admission. ${ }^{41}$

We believe that $\mathrm{BE}$ can have a significant impact in promoting completion of ADs. Ultimately, with an $\mathrm{AD}$ in place, patients and families may be better off in the long run and resources will not be spent on interventions that are unlikely to be effective or that can result in a greatly decreased quality of life.

\section{Defaults}

The discussion about defaults and ADs involves the medical paradigm that aggressive treatment will be provided to sustain life unless a patient specifically chooses otherwise. Changing this paradigm - through, for example, incorporating default options in ADs by stating the end-of-life goal is "quality of life" as opposed to "extension of life" - is fraught with ethical considerations and is beyond the scope of what a practitioner can do in an office visit. ${ }^{37}$ Instead, we focus on $\mathrm{BE}$ techniques to encourage patients to put an $\mathrm{AD}$ in place.

\section{Framing}

A loss-framed message to elderly patients is that if they do not have an $\mathrm{AD}$ in place, they have a significant chance of having no say in any critical decisions that must be made at the end of their life. On the other hand, a gain-framed message would be that if they do have an AD in place, there is a significant chance their wishes will be followed regarding critical decisions at the end of life.

For some individuals, framing of the facts about ADs may be effective. For most, any mention of numbers or statistics may make their eyes glaze over. Framing does not have to involve a presentation of numbers or statistics; rather, a simple alteration or addition of words can have an impact. Instead of simply asking patients "Have you considered advanced care planning - that is, what you want your end-of-life care to look like?" use framing. For example, you might add "Have peace of mind that your wishes will be followed." (gain) or "Know that you will 
not be an emotional or financial burden on your family." (loss). Moses ${ }^{24}$ suggests a similar framing strategy for promoting mammograms, appealing to patients that they can have peace of mind and that their family needs them to be around in the future.

Evidence shows that an important end-of-life goal for ill patients is not burdening loved ones, yet practitioners rarely discuss this as a rationale for completing an AD. Historically, ADs have been encouraged as a way to promote patient autonomy. ${ }^{42}$ Thus, in the case of ADs, a simple shift of focus of the arguments for having an AD may increase the perceived benefits of having one. Practitioners should use this evidence to motivate patients to begin the planning process.

\section{Social norms}

Individuals take strong cues from what those around them or what those similar to them are doing. Therefore, do not highlight undesirable behavior, such as telling patients that a low percentage of elderly adults have ADs. This sends the message that the patient is not that different from most people, and the likely outcome is that they will do nothing. Given that the overall fraction of elderly who have ADs is quite low, a better alternative is to tell stories.

Telling stories about positive experiences with ADs can make them seem more normative and promote social learning. Telling stories also appeals to individuals' emotions (system 1), which can strongly shape decisions.

\section{Commitment}

Once the patient has been introduced to the idea of an AD, he or she could be asked to sign a commitment to follow through with completion of the AD or to discuss his or her wishes with family members. The practitioner could also provide a one-page form that allows the patient to briefly state his or her wishes for end-of-life care with space for not only the patient but also family members to sign. This would indicate

Table 2 Summary of major behavioral economics strategies*

\begin{tabular}{|c|c|c|}
\hline Name of principle & Behaviors & Strategy with patients \\
\hline Affect/emotion & $\begin{array}{l}\text { Our emotional associations can powerfully affect our } \\
\text { actions; we make decisions based on emotion or affect, } \\
\text { not statistics }\end{array}$ & Use anecdotes and stories to emphasize a point \\
\hline Loss aversion & $\begin{array}{l}\text { Losing something causes us more mental anguish than } \\
\text { gaining something of the same value (loss aversion) }\end{array}$ & $\begin{array}{l}\text { Frame information as to what person may lose } \\
\text { rather than what they may gain }\end{array}$ \\
\hline Incentives & $\begin{array}{l}\text { We respond to prizes or privileges. Responses to } \\
\text { incentives are shaped by things such as strongly } \\
\text { avoiding losses }\end{array}$ & $\begin{array}{l}\text { Invent and offer incentives of some kind. Frame } \\
\text { information as to what person may lose rather } \\
\text { than what they may gain (strong loss aversion) }\end{array}$ \\
\hline Messenger & $\begin{array}{l}\text { We are heavily influenced by who communicates to us. } \\
\text { We value information more from those we trust } \\
\text { and respect }\end{array}$ & $\begin{array}{l}\text { Use your personal power in a positive way } \\
\text { with the patient. Try to earn their trust } \\
\text { and respect }\end{array}$ \\
\hline Salience & $\begin{array}{l}\text { We pay more attention to information that seems } \\
\text { relevant to us }\end{array}$ & $\begin{array}{l}\text { Make information or recommendations } \\
\text { personal and tailored }\end{array}$ \\
\hline Framing & $\begin{array}{l}\text { We are influenced by the way in which information } \\
\text { is presented to us }\end{array}$ & $\begin{array}{l}\text { Frame messages to patients when conveying } \\
\text { important information about treatment choice }\end{array}$ \\
\hline Commitments & We seek to be consistent with our public promises & $\begin{array}{l}\text { Ask for commitment (sign pledge, tell family } \\
\text { and friends) }\end{array}$ \\
\hline Norms & $\begin{array}{l}\text { We respond to social pressure and are strongly influenced } \\
\text { by what we think other people are doing }\end{array}$ & Use examples of others who take action \\
\hline Defaults & We tend to go with the flow of preset options & $\begin{array}{l}\text { Make it easier to decide to act versus not act } \\
\text { (eg, require opt-out) }\end{array}$ \\
\hline Priming & Our acts are often influenced by subconscious cues & Plan positive cues to stimulate patient choices \\
\hline Ego & We take actions that make us feel better about ourselves & Recognize and praise beneficial behaviors \\
\hline Present bias/discounting & $\begin{array}{l}\text { We have "present-bias" preferences, which means that } \\
\text { present benefits and costs are valued more than future } \\
\text { benefits and costs. In other words, we discount the future. } \\
\text { Thus, an immediate reward of } \$ 10 \text { is valued more than a } \\
\text { future reward of the same amount, and an immediate cost } \\
\text { of } \$ 10 \text { feels larger than a future cost of } \$ 10\end{array}$ & $\begin{array}{l}\text { Help patient consider present benefit of } \\
\text { behavior or cost rather than future benefit }\end{array}$ \\
\hline Rule of thumb & $\begin{array}{l}\text { We adopt rules of thumb to deal with limited information- } \\
\text { processing capacity }\end{array}$ & $\begin{array}{l}\text { Assess patient's common approach to decision } \\
\text { making. Try not to overwhelm patient with } \\
\text { information at one sitting }\end{array}$ \\
\hline
\end{tabular}

Note: *Selected behaviors are modeled after those by the Behavioural Insights Team. Data from: @ Crown copyright 20I0. Cabinet Office Behavioural Insights Team. Applying Behavioural Insight to Health. London, UK: Cabinet Office; 20I0. Available from: https://www.gov.uk/government/uploads/system/uploads/attachment_data/file/60524/403936_ Behaviourallnsight_acc.pdf. Accessed October 15, 2014. License details available from: http://www.nationalarchives.gov.uk/doc/open-government-licence/. ${ }^{20}$ 
that family members are aware of the patient's wishes and commit to following said wishes.

\section{Conclusion}

In summary, BE can provide nurse clinicians with a range of new powerful strategies that are evidence based to promote patient decision making. Nurses can be more strategic in working with patients to select new approaches that can enhance patient outcomes. As an aid, Table 2 provides a summary of many of the major BE strategies mentioned in this article that can be employed.

\section{Disclosure}

The authors report no conflicts of interest in this work.

\section{References}

1. Frank RG. Behavioral Economics and Health Economics. Diamond P, Vartiainen H, editors. Princeton, NJ: Princeton University Press; 2007: 195-234.

2. Garcia-Retamero R, Cokely ET. Effective communication of risks to young adults: using message framing and visual aids to increase condom use and STD screening. J Exp Psychol Appl. 2011;17(3):270-287.

3. Latimer AE, Salovey P, Rothman AJ. The effectiveness of gain-framed messages for encouraging disease prevention behavior: is all hope lost? J Health Commun. 2007;12(7):645-649.

4. O'Keefe DJ, Jensen JD. The relative persuasiveness of gainframed loss-framed messages for encouraging disease prevention behaviors: a meta-analytic review. J Health Commun. 2007;12(7): 623-644.

5. Rothman AJ, Salovey P. Shaping perceptions to motivate healthy behavior: the role of message framing. Psychol Bull. 1997;121(1):3.

6. Detweiler JB, Bedell BT, Salovey P, Pronin E, Rothman AJ. Message framing and sunscreen use: gain-framed messages motivate beachgoers. Health Psychology. 1999;18(2):189.

7. Grady JL, Entin EB, Entin EE, Brunyé T. Using message framing to achieve long-term behavioral changes in persons with diabetes. Appl Nurs Res. 2011;24(1):22-28.

8. Hibbard JH, Greene J, Sofaer S, Firminger K, Hirsh J. An experiment shows that a well-designed report on costs and quality can help consumers choose high-value health care. Health Aff. 2012;31(3): 560-568.

9. Nease RF, Glave Frazee S, Zarin L, Miller SB. Choice architecture is a better strategy than engaging patients to spur behavior change. Health Aff. 2013;32(2):242-249.

10. Persell SD, Friedberg MW, Meeker D, et al. Use of behavioral economics and social psychology to improve treatment of acute respiratory infections (BEARI): rationale and design of a cluster randomized controlled trial [1RC4AG039115-01]-study protocol and baseline practice and provider characteristics. BMC Infect Dis. 2013; 13(1):290.

11. Ubel PA, Jepson C, Baron J. The inclusion of patient testimonials in decision aids: effects on treatment choices. Med Decis Making. 2001; 21(1):60-68.

12. Thaler RH SC. Nudge: Improving Decisions about Health, Wealth and Happiness. New Haven CT: Yale University Press; 2008.

13. Kahneman D. Thinking Fast and Slow. New York, NY: Farrar, Straus and Giroux; 2011.

14. Mattke S, Liu H, Caloyeras JP, et al. Workplace Wellness Programs Study [webpage on the Internet]. RAND Corporation; 2013. Available from: http://www.rand.org/pubs/research_reports/RR254.html. Accessed September 2, 2014.
15. James J. Workplace Wellness Programs [webpage on the Internet]. Health Policy Brief, May 10, 2012. Available from: http://healthaffairs. org/healthpolicybriefs/brief_pdfs/healthpolicybrief_69.pdf. Accessed September 2, 2014.

16. Volpp KG, Asch DA, Galvin R, Loewenstein G. Redesigning employee health incentives - lessons from behavioral economics. $N$ Engl J Med. 2011;365(5):388-390.

17. Kamenica E. Behavioral economics and psychology of incentives. Annu Rev Econ. 2012;4(1):427-452.

18. Loewenstein G, Brennan T, Volpp KG. Asymmetric paternalism to improve health behaviors. JAMA. 2007;298(20):2415-2417.

19. stickK.com [homepage on the Internet]. stickK: the smartest way to set and achieve your goals; updated 2014. Available from: http://www. stickk.com/. Accessed September 2, 2014.

20. Cabinet Office Behavioural Insights Team. Applying Behavioural Insight to Health. London, UK: Cabinet Office; 2010. Available from: https://www.gov.uk/government/uploads/system/uploads/attachment_data/file/60524/403936_BehaviouralInsight_acc.pdf. Accessed October 15, 2014.

21. Dolan P, Hallsworth M, Halpern D, King D, Metcalfe R, Vlaev I. Influencing behaviour: the mindspace way. J Econ Psychol. 2012;33(1): 264-277.

22. Williams BR, Bezner J, Chesbro SB, Leavitt R. The effect of a behavioral contract on adherence to a walking program in postmenopausal African American women. Top Geriatr Rehabil. 2005;21(4): $332-342$.

23. McNeil BJ, Pauker SG, Sox HC Jr, Tversky A. On the elicitation of preferences for alternative therapies. $N$ Engl J Med. 1982;306(21): 1259-1262.

24. Moses J. Get action instead of indifference: using behavioral economics insights to deliver benefits messages. Benefits Q. 2013;29(3).

25. Agency for Healthcare Research and Quality. Patient decision aids. AHRQ effective health care program. Available from: http://effective healthcare.ahrq.gov/index.cfm/tools-and-resources/patient-decisionaids/. Accessed September 2, 2014.

26. Madrian BC, Shea DF. The power of suggestion: Inertia in 401 (k) participation and savings behavior. $Q J$ Econ. 2001;116(4): 1149-1187.

27. Health Affairs Blog. We're only human: behavioral economics and british policy (part 2). Available from: http://healthaffairs.org/ blog/2011/07/20/were-only-human-behavioral-economics-and-britishpolicy-part-2/. Accessed September 2, 2014.

28. Moyer VA. Screening for HIV: US preventive services task force recommendation statement. Ann Intern Med. 2013;159(1):51-60.

29. Slovic P. The construction of preference. Am Psychol. 1995;50(5):364.

30. Koppel R, Metlay JP, Cohen A, et al. Role of computerized physician order entry systems in facilitating medication errors. JAMA. 2005; 293(10):1197-1203.

31. Christakis NA, Fowler JH. The spread of obesity in a large social network over 32 years. N Engl J Med. 2007;357(4):370-379.

32. Bellis M, Hughes K, Cook P, Morleo M. Off Measure: How We Underestimate The Amount We Drink. London, UK: Alcohol Concern; 2009.

33. Johannessen K, Glider P. The University of Arizona's campus health social norms media campaign. In: Perkins H, ed. The Social Norms Approach to Preventing School and College Age Substance Abuse: A Handbookfor Educators, Counselors, and Clinicians. San Francisco, CA: Jossey-Bass; 2003.

34. Coleman S. The Minnesota income tax compliance experiment: state tax results. Minnesota Department of Revenue: 1996. Available from: http://www.revenue.state.mn.us/research_stats/research_reports/19xx/ research_reports_content_complnce.pdf. Accessed September 1, 2014.

35. Zimmerman FJ. Using behavioral economics to promote physical activity. Prev Med. 2009;49(4):289-291.

36. Kane RS, Burns EA. Cardiopulmonary resuscitation policies in longterm care facilities. J Am Geriatr Soc. 1997;45(2):154-157. 
37. Halpern SD, Ubel PA, Asch DA. Harnessing the power of default options to improve health care. $N$ Engl J Med. 2007;357(13): $1340-1344$.

38. Chiong W, Kim AS, Huang IA, Farahany NA, Josephson SA. Testing the presumption of consent to emergency treatment for acute ischemic stroke. JAMA. 2014;311(16):1689-1691.

39. The Commonwealth Fund. Quality matters: using behavioral economics to advance health, care [webpage on the Internet]. Available from: http:// www.commonwealthfund.org/Newsletters/The-Commonwealth-FundConnection/2013/Jul/July-8-2013/On-the-Web/Using-BehavioralEconomics-to-Advance-Health.aspx. Accessed September 2, 2014.
40. National Prescribing Centre. Statins patient decision aid. England: National Prescribing Centre; 2009. Available from: http://www.npc.nhs. uk/therapeutics/cardio/cd_lipids/resources/pda_Lipids.pdf. Accessed September 2, 2014.

41. Ehlenbach WJ, Barnato AE, Curtis JR, et al. Epidemiologic study of in-hospital cardiopulmonary resuscitation in the elderly. $N$ Engl J Med. 2009;361(1):22-31.

42. Steinhauser KE, Christakis NA, Clipp EC, McNeilly M, McIntyre L, Tulsky JA. Factors considered important at the end of life by patients, family, physicians, and other care providers. JAMA. 2000;284(19):2476-2482.

\section{Publish your work in this journal}

Patient Preference and Adherence is an international, peer-reviewed, open access journal that focuses on the growing importance of patient preference and adherence throughout the therapeutic continuum. Patient satisfaction, acceptability, quality of life, compliance, persistence and their role in developing new therapeutic modalities and compounds to optimize clinical outcomes for existing disease states are major areas of interest for the journal. This journal has been accepted for indexing on PubMed Central. The manuscript management system is completely online and includes a very quick and fair peer-review system, which is all easy to use. Visit http://www dovepress.com/testimonials.php to read real quotes from published authors.

Submit your manuscript here: http://www.dovepress.com/patient-preference-and-adherence-journal 